\title{
Sobre la relación verbalvisual en el humor gráfico y sus recursos
}

\section{Pedrazzini, Ana; Scheuer, Nora}

Resumen:

Estudiamos las diversas formas y grados en que los modos verbal y visual se relacionan en el humor gráfico multimodal, focalizando en las funciones que ambos asumen para construir la situación referida (tema) y la situación ficticia (juego humorístico) así como en los recursos verbales, visuales y mixtos utilizados. El corpus de viñetas humorísticas analizado fue obtenido a partir de un cuestionario en el que se solicitó a humoristas gráficos elegir una viñeta representativa de su estilo. Proponemos una gradación de la participación modal en la construcción de las situaciones referida y ficticia: distribución del trabajo modal (grado 1), conjunción parcial (grado 2) y total (grado 3).

\section{Cuadernos del Centro de Estudios de Diseño y Comunicación N74}

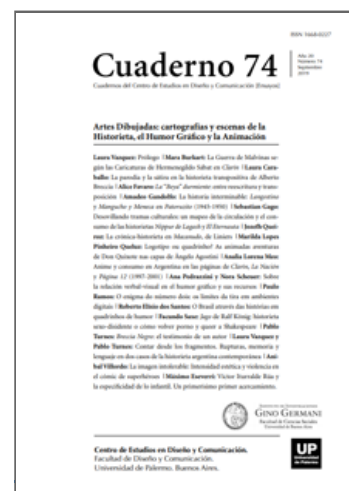

ISSN: 1668-0227

Artes Dibujadas:

cartografías y

escenas de la

Historieta, el Humor

Gráfico y la

Animación

Año XX, Septiembre 2019, Buenos

Aires, Argentina | 256 páginas

descargar PDF ver índice de la publicación

Ver todos los libros de la publicación

compartir en Facebook

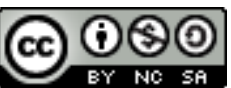

Esta obra está bajo una Licencia Creative Commons Atribución-NoComercialCompartirlgual 4.0 Internacional

Palabras clave: relación verbal-visual -

multimodalidad - intermodalidad - humor gráfico - recursos - figuras retóricas.

(*) Dra. en Ciencias de la Información y de la Comunicación y Dra. en Ciencias Sociales. Investigadora Asistente de CONICET en el Grupo Vinculado de Estudios Culturales y Cognitivos del Instituto Patagónico en Humanidades y Ciencias Sociales de CONICETUniversidad Nacional del Comahue. Sus investigaciones versan fundamentalmente sobre la producción de humor gráfico en profesionales y niños.

$\left.{ }^{* *}\right)$ Dra. en Psicología. Investigadora Principal de CONICET en el Grupo Vinculado de Estudios Culturales y Cognitivos del Instituto Patagónico en Humanidades y Ciencias Sociales de CONICET - Universidad Nacional del Comahue. En sus investigaciones se interesa principalmente por el desarrollo cognitivo y el aprendizaje de diversos modos semióticos. 
La abundancia y configuración dinámica de diversidad textos con los que interactuamos continuamente, informativos, argumentativos, de entretenimiento, pedagógicos, en los que participan simultáneamente los modos semióticos verbal y visual (según Martinec y Salway [2005] "los más ubicuos medios de comunicación") ha despertado un creciente interés en la comunidad académica. Un aporte pionero en este sentido fue el de Barthes (1964), quien distinguió las archi conocidas funciones de anclaje y relevo en la relación verbal-visual. Desarrollos ulteriores aplicados a diversos tipos de textos como los de Alonso Erausquín (1995) en la fotografía periodística; Gubern (1972), Groensteen (2007, 2011), McCloud (1994) y Peeters (1998) en la historieta; Unsworth y Cléirigh (2011) en libros escolares; Hoek (2002) en estampillas; entre otros, aportaron mayores precisiones en las formas de articulación entre ambos modos semióticos. El más reciente enfoque multimodal (Jewitt, 2009; Kress, 2010; Kress y Van Leeuwen, 2006; entre otros), con una reflexión integradora acerca de los recursos puestos en juego para construir y atribuir sentido en un amplio arco de situaciones sociales, ha asignado particular atención a las formas de articulación entre ambos modos. No obstante, continúa vigente la necesidad de contar con un mayor bagaje de trabajos analíticos que teoricen sobre su estructuración y funcionamiento (Martinec y Salway, 2005).

El humor gráfico ofrece un terreno propicio para profundizar este tema, en tanto buena parte de las producciones que lo conforman articulan en diversos grados el dibujo y la escritura para dar lugar a un todo significante de notable síntesis y densidad semiótica.

El humor gráfico multimodal: multiplicidad de signos en estrecha articulación

Las viñetas humorísticas que articulan el dibujo y la escritura constituyen discursos multimodales en los que interactúan multiplicidad de signos icónicos, plásticos (Grupo Mu, 1992; Joly, 2005) y lingüísticos al servicio de una intencionalidad comunicativa y expresiva, con la finalidad última de denunciar, criticar, suscitar la reflexión, descargar tensiones y/o divertir. Tanto la producción como la interpretación de este tipo de discursos es simultánea (Hoek, 2002), es decir que los modos semióticos son convocados al mismo tiempo y uno no funciona independientemente del otro. Cada modo, desde su especificidad semiótica, aporta de manera sustancial a la producción de sentido. Mientras que el principio de organización principal de la escritura es secuencial, en la imagen es simultáneo. La imagen se enmarca espacialmente, siendo la disposición de cada elemento en ese espacio crucial (Kress, 2010). Además, las palabras no pierden su individualidad y responden a reglas gramaticales precisas, contrariamente a las imágenes que pueden ser fácilmente subsumidas en un todo más vasto y generadas a partir de principios menos normados. Las imágenes pueden sufrir transformaciones o manipulaciones espaciales significativas (ver Gross, 2009) como la deformación en la caricatura. Teniendo estas particularidades en mente, vemos que aún en casos en los que existe cierto solapamiento en la presentación de la información por parte de uno y otro modo semiótico, éste no alcanza a constituir una genuina redundancia.

En un estudio sobre la relación de la imagen y la escritura, Hoek (2002) distingue cuatro grados de cercanía entre los modos visual y verbal que contribuyen a delimitar el caso particular del humor gráfico: transposición, colocación, conjunción y fusión. La transposición tiene lugar cuando uno de los modos reenvía al otro en un momento posterior, como la crítica a una pintura (aquí el modo visual origina el verbal) o una película inspirada de una novela escrita (aquí inversamente el modo verbal origina el visual). En este caso, contamos con dos textos separados: aunque el segundo existe en base al primero, cada uno puede ser leído por sí mismo. La colocación se da cuando ambos modos son reunidos en un mismo texto, como ocurre en los libros ilustrados. Los modos son yuxtapuestos y mantienen cierta autonomía; de hecho podrían ser separados y constituirse 
como dos textos, uno verbal y otro visual. La tercera categoría, en la que ubicamos a las viñetas humorísticas multimodales, implica una conjunción entre modos. Ambos son combinados en una relación de complementariedad. Tanto lo verbal como lo visual dejan de ser autónomos ya que si fuesen leídos independientemente, perderían el sentido que resulta de su interacción: el texto (Vilches, 1984) mixto así constituido significa más que la suma de los elementos que lo componen. La fusión, por último, es el más alto grado de co-occurrencia modal y sucede cuando ambos modos son materialmente inseparables: constituyen una "amalgama" verbal-visual, un texto sincrético. Un buen ejemplo de este sincretismo es el caligrama.

La conjunción de lo verbal y lo visual en las viñetas humorísticas no asegura que ambos modos efectivamente contribuyan a alcanzar el efecto humorístico. Samson y Huber (2007) identificaron tres tipos de articulación funcional entre modos para la generación de humor gráfico: el humor se produce en el modo verbal mientras que lo visual sólo interviene de forma ilustrativa; el humor se produce en el modo visual, lo verbal puede ser incluso innecesario; y por último, el humor resulta de la interacción entre ambos modos. Proponemos -en sintonía con trabajos como el de Tsakona, 2009- que en el caso de interacción, lo verbal y lo visual pueden operar de forma convergente o divergente. En la convergencia, ambos modos aportan sentidos que confluyen en una o más ideas relacionadas. La contribución puede ser pareja, siendo la relación de complementariedad, o bien un modo puede predominar sobre el otro. Vemos así que dentro de la conjunción verbalvisual propuesta por Hoek, la complementariedad no es el único caso. En la divergencia, lo verbal y lo visual aportan sentidos que se contraponen en cierto grado, siendo esta contradicción deliberada, al punto de contribuir, en ocasiones, a la generación de humor.

Síntesis y densidad en la construcción de la situación referida y la situación ficticia

Las viñetas humorísticas conforman textos que se caracterizan por ser sintéticos y condensados, presentando pocos elementos verbales y visuales altamente significativos para la elaboración del mensaje que se desea difundir.

Esta síntesis y densidad intervienen en los dos componentes insoslayables de toda viñeta humorística: la situación referida y la situación ficticia o juego. La situación referida remite al tema abordado. Para que la viñeta se inscriba en el género humorístico, esta situación referida tiene una "contracara", que es la situación ficticia instaurada por el autor (EI Refaie, 2009; Pedrazzini y Scheuer, 2010). En esta construcción o recreación opera una incongruencia, una ruptura de lo previsible (Attardo, 1994; Fourastié, 1983; Pedrazzini, 2015). El autor juega con lo insólito, absurdo, ridículo, deformado y/o exagerado, articulando un sentido literal y uno o más sentidos latentes. Para ello pone en juego un amplio abanico de recursos. Algunos de estos recursos trascienden el campo humorístico, como es el caso de las figuras retóricas, que activan simultáneamente sentidos propios y figurados. Otros recursos son más específicos del humor, como el absurdo, la inversión de roles, la parodia y el travestimiento con fines satíricos o lúdicos.

Las clasificaciones tradicionales de las figuras retóricas distinguen cuatro grupos principales, atendiendo a los niveles en que se produce la operación retórica: fonográficos, semánticos, sintácticos o referenciales. Las figuras de palabras se basan en juegos léxicos y sonoros; las figuras de sentido comprenden los tropos (metáfora, metonimia y sinécdoque) y otras figuras que sirven para enriquecer la o las significaciones de una palabra $u$ otro elemento al utilizarlas en un contexto inesperado (Robrieux, 1993); las figuras de construcción se centran en la 
sintaxis; y las figuras de pensamiento refieren a la relación del enunciado/texto con el autor y con su objeto, el referente (Reboul, 1993).

Esta tetrapartición ha sido criticada por algunos expertos al constatar una interdependencia de los cuatro niveles, así como una dimensión transfrástica operando en las figuras. La idea de que hay un "continuum" (Fromilhague, 2005, p. 20) entre dichos niveles aporta una visión más dinámica sobre cómo operan las figuras.

Este tipo de clasificaciones puede aplicarse tanto a lo lingüístico como a lo icono-plástico. La pertinencia de una retórica aplicada a la imagen fue postulada ya hace décadas por, entre otros, Roland Barthes (1960), Dominique Durand (1970) y el Grupo $\mu$ (1992).

Como hemos señalado, las figuras retóricas juegan un rol central en los discursos humorísticos pero no pueden calificarse como recursos humorísticos en sí, pues intervienen también en otro tipo de discursos. Algunos recursos habituales más específicamente humorísticos son el absurdo, la parodia, el travestimiento y la inversión de roles1. El absurdo consiste en un sin sentido que no puede someterse a una interpretación racional. Asocia universos semánticos que no guardan relación entre sí (Charaudeau, 2006). La parodia opera transformando un texto, un autor o un estilo de relativamente alta circulación social, con fines lúdicos o satíricos. La distorsión puede ser de toda la obra o de una parte de ella, siendo la obra original, el hipotexto (Genette, 1987), el foco de la transformación. Tillier (2005, p. 216) señala que para que funcione el juego paródico la referencia debe cumplir tres criterios: "tener una composición clara que preserve su identificación, poseer una apertura semántica suficiente que la torne utilizable en un nuevo contexto, estar dotada de una celebridad que garantice su reconocimiento por un público lo más vasto posible". Un recurso próximo a la parodia es el travestimiento o préstamo textual con fines satíricos o lúdicos, que entendemos como una operación a partir de la cual se transforma un texto original al insertarlo en otro contexto sin que el foco sea ese texto original, el hipotexto. El préstamo permite actualizar una referencia cultural externa a la situación referida. La inversión consiste en dar vuelta una situación o invertir los roles, como es el caso típico del ladrón al que le roban (Bergson, 2008).

Un análisis semiótico y retórico en un corpus selecto de viñetas humorísticas

Teniendo en cuenta la revisión presentada, en este trabajo apuntamos a responder a las siguientes preguntas: ¿Cómo operan los modos semióticos en la situación referida y en la situación ficticia en un corpus variado de viñetas humorísticas multimodales? ¿Hay recursos que operen más cómodamente en alguno de los modos de funcionamiento básico considerados: predominantemente verbal, visual o mixto? ¿Cuándo se registra una distribución del trabajo semiótico y cuándo en vez lo realizan conjuntamente? ¿Es posible establecer una gradación en la articulación entre modos?

En estudios anteriores (Pedrazzini, 2012; Pedrazzini y Scheuer, 2010, 2012) hemos analizado la participación verbal, visual y mixta en la construcción de la situación referida y ficticia así como la diversidad de figuras retóricas que operan en esta última en un subgénero específico, el de la caricatura política. En los dos corpus argentino y francés estudiados (475 caricaturas políticas en total), identificamos cuatro tipos de funcionamiento: el juego es verbal, el juego es visual, el juego es mixto convergente complementario o mixto divergente, siendo el juego verbal mucho más recurrente en ambos corpus. Cada caricatura presentaba entre una y dos figuras, con una mayor frecuencia y diversidad de figuras verbales que visuales. Las figuras de asociación fueron las 
más recurrentes en el modo visual mientras que la ironía y sus variantes y otras figuras de pensamiento, como la alusión, fueron más habituales en el modo verbal.

En el presente trabajo, además de extender el estudio semiótico y retórico a otros subgéneros dentro del humor gráfico que trascienden la actualidad política (actualidad no política, viñetas atemporales), nos interesa también realizar un análisis de la estrecha articulación de los modos verbal y visual en el plano de las figuras retóricas y los recursos humorísticos específicos, es decir aquellos que podemos llamar genuinamente mixtos.

\section{El corpus}

Trabajamos con un corpus de viñetas humorísticas que fueron elegidas por humoristas gráficos profesionales como aquellas producciones más representativas de su estilo. Dicha elección se dio en el marco de un cuestionario que estaba estructurado en torno a cuatro ejes temáticos: antecedentes personales, modalidad de trabajo, visión sobre el humor gráfico, visión sobre la obra personal. El cuestionario fue escrito en español, francés e inglés y se distribuyó a la mayor cantidad posible de profesionales, fundamentalmente vía correo electrónico, de forma individualizada o a través de organismos o instituciones que nuclean a humoristas gráficos.

El cuestionario fue respondido por 90 humoristas gráficos de 22 nacionalidades (de Europa, 56\%; Hispanoamérica, 30\%; América del Norte, 9\%; Asia, 3\% y África, 2\%). Dado que en este estudio focalizamos en la articulación verbal-visual, excluimos las viñetas puramente visuales (39\% del total de producciones elegidas) así como las tiras ( $5 \%$ del total), en tanto estas últimas presentan características estructurales diferentes que ameritarían otro tipo de análisis. El corpus así constituido comprende 50 viñetas multimodales de un solo panel. Las mismas pertenecen a diversos subgéneros del humor gráfico: viñetas de actualidad política, viñetas de actualidad no política, viñetas atemporales.

Análisis de las producciones

Realizamos un análisis semiótico y retórico de las viñetas a dos niveles: a nivel macro, identificar y analizar las distintas funciones asumidas por los modos verbal y visual y las formas de interactuar respecto a la construcción de la situación referida y la situación ficticia; a nivel micro, identificar y estudiar los diversos recursos verbales, visuales y mixtos utilizados para generar la situación ficticia.

Para ello, utilizamos un procedimiento de categorización que combina la aplicación y adaptación de las categorías conceptuales revisadas previamente con los patrones observados en el corpus. Cada viñeta fue categorizada en función de los dos niveles:

- La contribución de los modos semióticos en la construcción de las situaciones referida y ficticia. Las categorías son: verbal, visual, mixto.

- Las figuras retóricas y los recursos humorísticos específicos según el modo semiótico en el que operan.

Manteniendo la tetrapartición tradicional de las figuras retóricas (ver apartado anterior) pero conscientes del continuum entre las clases señalado por Fromilhage, en este trabajo adaptamos la clasificación de figuras propuesta por Beth y Marpeau (2005), dividiendo algunos grupos en función de la importancia cualitativa y cuantitativa de los tipos de figuras detectados en el corpus analizado. Dado el foco multimodal de este estudio y 
su baja frecuencia detectada en el corpus, descartamos las figuras de palabras. El grupo de figuras de sentido fue dividido en tres (contigüidad, asociación y doble sentido) y el de pensamiento en dos grupos (ironía y sarcasmo y otras figuras de pensamiento) (Ver Tabla 1).

Los recursos humorísticos específicos que distinguimos son: absurdo, inversión de roles, parodia/travestimiento.

Ambas autoras categorizaron independientemente todas las viñetas. Los casos de desacuerdo fueron resueltos en su totalidad por discusión. En un $20 \%$ de los casos, la comparación de los análisis permitió incrementar la cantidad de recursos identificados en cada viñeta, lo cual es entendible considerando la riqueza semiótica y retórica inagotable de los modos verbal y visual. Posteriormente, aplicamos la prueba chi cuadrado para establecer la dependencia entre situaciones (referida y ficticia) y modos semióticos; así como entre categorías de recursos y modos semióticos. Luego aplicamos los Residuales estandarizados (Haberman, 1973) para identificar aquellas categorías sobre y sub-representadas en los casos de dependencia.

\section{Resultados}

Funcionamiento de los modos semióticos en la construcción de las situaciones referida y ficticia

Se encontró una diferencia significativa en la construcción de las situaciones referida y ficticia según los modos semióticos intervinientes $\left(X^{2}=15,7, g l=2, p=<0.001\right)$. Como puede apreciarse en la Figura 1 , tanto la situación referida como la ficticia se construyen predominantemente a partir de la interacción verbal-visual. La articulación entre los modos se encuentra sobre-representada en la situación ficticia, en tanto que el modo verbal está sobrerepresentado en la construcción de la situación referida (Ver Tabla 2). Se registra un sólo caso en el que el juego se construye únicamente a través del modo verbal.

Si atendemos a la construcción de las situaciones referida y ficticia al interior de cada viñeta (Ver Tabla 3), observamos que los dos comportamientos más comunes son: o bien ambas se construyen de forma mixta o bien la situación referida es verbal y la ficticia es mixta.

Esta preeminencia del modo mixto en la construcción de una o ambas situaciones referidas nos lleva a adentrarnos en su funcionamiento. Son contados los casos en los que la construcción mixta produce sentidos divergentes. Dentro de la convergencia, identificamos tres casos diferentes. Cuando ambos modos aportan elementos no contemplados en el otro modo que son igualmente relevantes para la producción de sentido, de forma que éste resulta de la interacción entre los dos, hablamos de complementariedad. Si la contribución no es pareja sino que un modo predomina sobre el otro, puede ocurrir que uno de ellos esté reforzando o ampliando elementos provistos por el otro modo, o bien que un modo sea parcialmente redundante (como hemos dicho, la especificidad de cada modo semiótico no habilita una redundancia total).

A continuación analizaremos viñetas del corpus que nos permiten comprender mejor los funcionamientos mencionados en el modo mixto.

Situaciones referida y ficticia mixtas convergentes. 
La situación referida de la Figura 2 es doble. Por un lado, es explícita en el modo verbal, los Juegos Olímpicos de 1992. Esta referencia a los juegos es reforzada en el modo visual, mediante el símbolo de los cinco anillos entrelazados. Por otro lado, hay una referencia implícita a la Guerra del Golfo, vehiculizada en el modo visual mediante el militar y el tanque. El hecho de abordar dos acontecimientos no directamente relacionados en el humor gráfico es un recurso usual. La complementariedad en la construcción de la situación referida doble es relativa, o al menos distinta a lo que sería que surja ineluctablemente de la interrelación verbal-visual.

El juego de lenguajes que construye el humorista Vincent es variado y denso. Los anillos entrelazados funcionan como silepsis al remitir también a las ruedas del tanque. La metáfora visual del desfile militar y deportivo, asociada a la medalla del militar y su actitud triunfalista, introducen una crítica y denuncian con cinismo una postura de disfrute ante la beligerancia. La crítica opera también de forma mixta mediante la ironía de la frase "Lo esencial es participar", que supone el travestimiento de un slogan conocido y que sólo cobra su sentido en relación con la imagen. El desfile militar también alude a las conquistas de los invasores cuando toman una ciudad o a su liberación, tal como ha sucedido a lo largo de la historia (las ciudades francesas en la Segunda Guerra Mundial, por ejemplo). Por último, el dibujo de chinches le da a la viñeta el status de póster y la chinche caída connota, metonímicamente, cierta dejadez o decadencia.

\section{Refuerzo o ampliación}

La situación referida de la Figura 3 -la desigualdad social- opera de modo mixto, lo verbal reforzando o ampliando cierta información vehiculizada en el modo visual: "Carton. cl, Fletes, Taxi, Escolar". Los carteles "Partida" y "Meta" participan de la situación ficticia reforzando -al límite de una redundancia- la metáfora de la carrera. La paradoja mixta de la limousine, que ya está en la meta, introduce sarcásticamente la visión del humorista Gai, quien logra valerse de muy pocos elementos para representar este problema social endémico y (cuasi)universal. La disposición de los vehículos, gradación que va de lo más modesto a lo más costoso, se asocia con la metonimia de cada vehículo que remite a las clases sociales. La antítesis contribuye a subrayar las desigualdades: en los tamaños entre la limousine (hipérbole) y los demás vehículos, en la postura derecha y firme del pasajero y del conductor de la limousine que contrasta con la postura encorvada del resto. La actitud del banderista, dispuesto a cumplir su función, resulta absurda y lúdica.

\section{Redundancia parcial}

La situación referida de la Figura 4 remite a la Masacre de la Plaza de Tian'anmen. La situación referida es implícita y existe una fusión entre ésta y la situación ficticia puesto que los elementos que permiten identificar el hecho, también sirven para construir el juego. En ambas el modo verbal interviene puntualmente, con la etiqueta de la tinta china que redunda con la imagen predominante. Como la tinta china mantiene en su nombre su origen, el humorista JL Savignac refuerza la identificación del mapa de China trazado por la tinta roja derramada, recurso metonímico para aludir a la crudeza de los acontecimientos que tuvieron lugar en Pekín en 1989.

Situación referida verbal - situación ficticia mixta convergente

En la Figura 5, el humorista Chumbi ancla la situación referida -tomar cursos de pesca a distanciaprincipalmente con el modo verbal. Si bien en el modo visual se observa a un hombre pescando, la idea de curso a distancia es actualizada con el título del libro dibujado. La presencia verbal se articula asimismo con la 
imagen para construir la situación ficticia. Es fundamentalmente con la metonimia de la canilla que reenvía al agua, que el autor propone una mirada absurda y lúdica sobre una práctica cultural muy extendida a lo largo y ancho del mundo. Una segunda lectura supone una crítica hacia la utilidad y pertinencia de ciertos cursos a distancia, acentuada en el caso de la pesca, que implica el disfrute de la naturaleza. El escenario representado, la paradoja irónica y el absurdo cumplen su cometido de construir una situación que resulta incongruente y con potencial lúdico.

Situación referida mixta convergente - situación ficticia mixta divergente

La situación referida de la Figura 6 puede inferirse a partir de la interacción verbal-visual. La viñeta fue producida por Plantu para el diario francés Le Monde en 2006, cuando la publicación de una serie de caricaturas de Mahoma por un periódico danés suscitó hechos de violencia en distintos países de Europa y Asia. El humorista gráfico se implica a sí mismo explícitamente a partir de la mano y el lápiz que por sinécdoque remiten al dibujante así como también del ratón, sello de Plantu presente en todas sus viñetas, que en esta oportunidad sostiene una carpeta de dibujos y se alerta ante la obra producida. Plantu hace de su producción un acto de protesta fuerte a favor de la libertad de expresión, desafiando ante las narices del imam que vigila, el mandato del islam que prohibe la representación del profeta. Como en la Figura 3, la situación referida se funde con la ficticia en tanto es la escritura, a la vez imagen, la que permite anclar el hecho. El caligrama, como vimos un claro ejemplo de sincretismo entre el dibujo y la escritura, introduce aquí una paradoja, de ahí la divergencia. La repetición de la frase "No debo dibujar a Mahoma" resulta irónica ante el resultado obtenido, al mismo tiempo que hace alusión, parodiando de cierta manera el disciplinamiento escolar de antiguas generaciones. La parodia introduce una crítica punzante ante los principios del islamismo, asociándola a un método disciplinar obsoleto y destinado a niños y adolescentes. Podríamos decir que esta viñeta adquiere un tono aún más contestario en la actualidad, luego de los atentados terroristas acontecidos en París en enero de 2015.

Recursos verbales, visuales y mixtos para la generación de humor

Pasamos ahora al nivel micro de este análisis, que focaliza en los recursos puestos en juego para construir la situación ficticia. Un primer resultado a señalar con respecto al conjunto de recursos identificados en este corpus es su densidad retórica, ya que la proporción es de prácticamente 6 por viñeta. El total de recursos se distribuye de forma muy despareja según los modos semióticos implicados $\left(x^{2}=62,44, g l .12 ; p=<0.001\right)$ : 46 son verbales mientras que 139 son visuales y 109 mixtos. La baja frecuencia de recursos verbales se condice con la cuasi inexistencia de situaciones ficticias construidas exclusivamente mediante signos lingüísticos (ver Figura 1). Sin embargo, no puede establecerse una relación directa entre los modos semióticos de los recursos y la construcción de la situación ficticia puesto que cuando ésta es construida de forma mixta, puede haber recursos puros (verbales y visuales) o mixtos. De hecho, lo que observamos en este estudio es que aún cuando la situación ficticia es mayormente mixta, son los recursos visuales los más numerosos.

La Figura 7 permite apreciar que en los recursos verbales, las figuras de pensamiento y de construcción suman más del $50 \%$ de los casos, con la alusión principalmente en las primeras y la repetición en las segundas. En los recursos visuales, son las figuras de contigüidad, construcción y pensamiento las más numerosas (60\% de los casos) mientras que en los recursos mixtos las figuras de pensamiento y los recursos humorísticos específicos totalizan $57 \%$ de los casos. Vemos así que las figuras de pensamiento resultan particularmente operativas para los humoristas gráficos en los tres funcionamientos modales básicos. 
La Tabla 3 muestra que ningún recurso verbal presenta casos de sobre o sub-representación. En el caso de los recursos visuales, están sobre-representadas las figuras de contigüidad y de construcción mientras que están sub-representadas la ironía y el sarcasmo y los recursos humorísticos específicos. Los recursos mixtos, por su parte, presentan un comportamiento inverso a los visuales: la ironía y el sarcasmo y los recursos humorísticos específicos presentan una distribución superior a la esperada mientras que en las figuras de contigüidad y de construcción su distribución es inferior a la esperada. La ausencia de casos de sobre o sub-representación en las figuras de asociación, doble sentido y pensamiento indica que estos recursos operan cómodamente en los tres modos de funcionamiento considerados.

Las figuras de contigüidad -metonimias y sinécdoques- encuentran en el dibujo un terreno propicio para operar. En éstas, el desplazamiento del sentido propio al sentido figurado se da por un razonamiento deductivo. Mientras que la metonimia se basa en una contigüidad lógica, la sinécdoque se funda en una relación de inclusión. Ambas figuras tienen un alto poder de condensación (Fromilhague, 1995; Bacry, 1992); de ahí que sean recursos tan extendidos en el humor gráfico.

La metonimia es particularmente útil ya que permite designar un elemento mediante otro elemento del mismo conjunto. Un caso es el de representar el envase por su contenido, como ocurre en la Figura 5, en la que la canilla remite al agua corriente. Otro caso es el de designar un agente o un concepto abstracto mediante un instrumento característico, como ocurre en la Figura 2, en la que el tanque evoca la guerra.

La sinécdoque resulta efectiva en el modo visual ya que toda imagen opera fraccionando el mundo y mostrando sólo una parte. El fragmento toma el valor del todo (Rojas Mix, 2006). La sinécdoque permite representar la parte por el todo o viceversa, la especie por el género o viceversa. En la Figura 6, la mano y el lápiz designan al humorista gráfico -a la profesión y en particular al propio Plantu- así como el imam remite al islamismo.

Entre las figuras de construcción, la antítesis es muy utilizada en el dibujo pues resulta eficaz para contrastar objetos, ideas, personajes, valiéndose además de componentes plásticos como formas, tamaños, disposición espacial y colores. Este recurso permite al humorista presentar clara y enfáticamente dos posturas antagónicas valiéndose de muy pocos elementos. En la Figura 3, la desigualdad entre clases es representada al oponer posturas corporales de los personajes, disposición y tamaño de los vehículos.

La ironía y el sarcasmo suelen convocar el modo mixto en este corpus y en cambio, son menos habituales en el visual. Son figuras que operan de forma implícita y oblicua manipulando el valor de verdad del enunciado (Fromilhague, 2005) por lo que exigen un razonamiento rebuscado que pareciera menos viable en el dibujo por sí solo. Resulta interesante detectar que de todos los grupos de figuras retóricas sean éstas las que mejor se adaptan a la estrecha articulación verbal-visual. En la Figura 4, la frase "Lo esencial es participar" cobra su sentido irónico en relación con la imagen. De hecho, si ésta no existiese y sólo leyésemos el título "1992. Año Olímpico" probablemente la interpretaríamos no en el sentido contrario sino en su sentido literal; el riesgo que corre el autor cuando el receptor no cuenta con la información necesaria que le permite advertir la ironía.

El modo mixto también es el privilegiado en los recursos más específicos del humor -el absurdo, la parodia o el travestimiento y la inversión de roles. De estas tres categorías, la parodia es la más recurrente que como vimos anteriormente, está muy emparentada con el travestimiento. La Figura 8 es un ejemplo de parodia ya que retoma irónicamente una frase pronunciada por el republicano Christopher Christie, "Obama doesn't know how 
to lead" (Obama no sabe liderar). La parodia se da por la combinación de los dos modos semióticos ya que cobra su sentido al ver a los dos políticos republicanos caricaturizados como perros dirigidos por la derecha. La Figura 9 es un ejemplo de travestimiento puesto que el personaje ET no es el blanco de la operación crítica y a la vez lúdica llevada a cabo por el humorista Puglia sino que es recuperada para trasponerla a otro contexto, el de la crisis económica europea. Distinto al caso anterior, en el que la parodia se da a partir de la interacción de los modos verbal y visual, aquí el travestimiento es fundamentalmente visual, reforzado con el modo verbal. En ambas figuras resulta esencial la caricatura de los políticos representados, Mitch McConnell y John Boehmer en la Figura 8, y Herman van Rompuy en la Figura 9, quien fue hasta 2014 Presidente del Consejo Europeo.

En la Figura 8 vemos igualmente un ejemplo de inversión de roles ya que McConnell y Boehmer se quejan de que el presidente Obama no sabe liderar mientras que ellos mismos no son representados como líderes políticos sino como perros conducidos mediante una soga.

\section{Conclusiones y discusión}

Este trabajo nos permitió analizar, en un corpus variado de viñetas humorísticas, las diversas formas y grados en que los modos verbal y visual se relacionan, a nivel macro, para construir la situación referida y la situación ficticia presentes en toda viñeta. A nivel micro, estudiamos además el uso que los humoristas gráficos hacen de las figuras retóricas y de recursos más específicos del género (absurdo, parodia, travestimiento, inversión de roles) a través de los diversos modos semióticos (verbal, visual, mixto).

En la mayor parte de los casos, los modos semióticos verbal y visual intervinieron conjuntamente tanto en la creación de la situación referida como de la ficticia. Sigue en frecuencia la participación verbal en la situación referida y mixta en la ficticia. Tan sólo una vez el juego se instauró movilizando exclusivamente el modo verbal y cinco el visual, por lo que podemos afirmar que en la elección de su viñeta representativa, los autores privilegiaron una conjunción (Hoek, 2002) estrechamente intermodal.

Un análisis funcional más en profundidad de la forma en que el dibujo y la escritura se articulan en las situaciones referida y ficticia hizo posible detectar cuatro funciones diferentes dentro de los casos de intermodalidad. La complementariedad y la divergencia (ésta muy poco frecuente en nuestro corpus) son los más netos ejemplos de conjunción, en los que ambos modos participan con una intensidad comparable, a la producción de sentido. El refuerzo o la ampliación, ya sea verbal o visual, implican que uno de los modos agregue o subraye información ya vehiculizada a través del otro medio. En la redundancia, por su parte, existe cierto solapamiento parcial -nunca total debido a la especificidad semiótica de cada modo- en la presentación de la información, ya sea verbal como visual. Estos dos últimos casos implican un predominio de uno de los modos semióticos. En suma, si integramos los resultados obtenidos a partir de los niveles de análisis macro y micro, podemos establecer una gradación de los funcionamientos modales en las viñetas humorísticas en las que se registran signos verbales y visuales (ver Tabla 4).

En el menor grado de articulación se evidencia una Distribución del trabajo de construcción de las situaciones referida y ficticia entre los modos verbal y visual: el verbal produce la situación referida mientras que el visual se ocupa de la ficticia. Ambos modos juegan un rol indispensable pero netamente diferenciado en la viñeta humorística. Un grado mayor de articulación, el de Conjunción parcial, se registra cuando los dos modos colaboran conjuntamente en la construcción de una de las dos situaciones intervinientes en la viñeta: o bien la 
situación referida o bien la ficticia es mixta (en nuestro corpus este caso es el más frecuente: ver Tabla 3). El mayor grado se da en la Conjunción Total, cuando ambos modos contribuyen en la construcción tanto de la situación referida como de la ficticia. Este máximo grado de intermodalidad se constata en más de la mitad del corpus analizado, lo cual da cuenta del esfuerzo de los autores de sacar máximo provecho de la relación verbalvisual. Cabe destacar que la conjunción (sea parcial o total) es aún más intensa cuando en la situación ficticia las figuras retóricas y/o los recursos humorísticos específicos surgen en el modo mixto.

Resulta interesante destacar que cuando la situación referida es implícita, se evidencia cierta fusión con la situación ficticia, lo cual es entendible en tanto lo implícito implica la decodificación de sentidos latentes que muchas veces operan conjuntamente con un lenguaje figurado. En estos casos podríamos afirmar que hay un grado relativamente alto de cercanía entre la situación referida y la ficticia.

Como vimos, no puede establecerse una relación directa entre los modos semióticos de los recursos y la construcción de la situación ficticia. Notamos que si bien los casos mixtos convergentes son los más habituales, son los recursos visuales los más frecuentes ( $47 \%$ del corpus). Los autores dieron mucha importancia al dibujo y a su potencial en la elección realizada, ya sea con fines argumentativos, lúdicos o de impacto.

Las producciones presentaron una alta densidad semiótica y retórica, con casi 6 recursos por viñeta. Este resultado contrasta con aquél obtenido en un corpus de caricaturas polí- ticas, donde además los recursos verbales fueron mucho más numerosos que los visuales (Pedrazzini, 2012; Pedrazzini y Scheuer, 2010). En el presente estudio, las figuras retóricas y los recursos humorísticos específicos utilizados variaron significativamente según los modos semióticos visual y mixto. En el primer caso, las figuras de contigüidad y de construcción encontraron en el dibujo un terreno predilecto, aportando eficazmente a los fines de condensación, contraste e impacto tan centrales en el humor gráfico. La ironía y el sarcasmo y los recursos específicos, por su parte, fueron más característicos del modo mixto. Estas figuras, contrariamente a las anteriores, requieren casi ineluctablemente la actualización de elementos ajenos al enunciado/texto para su interpretación. En este sentido, Molinié (1993) habla de figuras macroestructurales, que distingue de las microestructurales, que sí pueden identificarse y aislarse en el texto puesto que están ligadas a la materialidad de los elementos formales del discurso. Sería productivo a futuro ahondar en el estudio de los recursos mixtos, no sólo para verificar si esta tendencia se mantiene sino también para entender mejor por qué estas figuras operan más cómodamente en el modo mixto. Asimismo, también resultaría de particular interés investigar el funcionamiento de los signos plásticos como un modo semiótico con sus limitaciones y potencialidades específicas. Como vimos, este tipo de signos trabajan conjuntamente con los icónicos en toda imagen. La articulación tan estrecha entre los signos verbales y visuales y las diversas capas en los que operan para la producción de sentido configuran un complejo entramado funcional. Las numerosas imbricaciones sígnicas dificultan los esfuerzos analíticos, por lo que es necesario trascender la concepción de cada categoría como estanca y uniforme para pensar en modos de funcionamiento más continuos, permeables y dinámicos.

Notas

1. Más allá de que la mayoría de estos recursos pueden constituir géneros discursivos en sí, en las viñetas operan como procedimientos puntuales.

Agradecimientos 
Agradecemos a todos los humoristas gráficos que colaboraron con esta investigación contestando nuestras preguntas y eligiendo una/s viñeta/s representativa/s de su obra. En particular, a los humoristas gráficos que nos autorizaron a publicar sus viñetas en este artículo. Esta investigación cuenta con el financiamiento de la Agencia Nacional de Investigaciones Científicas y Técnicas (proyecto PICT 2014-2929), de CONICET (PIP 0142) y de la Universidad Nacional del Comahue (C-130).

\section{Referencias}

Alonso Erausquín, M. (1995). Fotoperiodismo: Formas y Códigos. Madrid: Síntesis.

Bacry, P. (1992). Les figures de style. París: Belin.

Barthes, R. (1964). Rhétorique de l'image. Communications, 4, 40-51.

Bergson, H. (2008). La risa. Ensayo sobre la significación de lo cómico. Madrid: Alianza.

Beth, A. y Marpeau, E. (2005). Figures de style. París: Librio Mémo.

Charaudeau, p. (2006). De nouvelles catégories pour l'humour? Questions de communication, 10, 19-41.

Durand, J. (1970). Rhétorique et image publicitaire. Communications, 15(1), 40-51.

El Refaie, E. (2009). Multiliteracies: how readers interpret political cartoons. Visual communication, 8(2): 181205.

Fourastié, J. (1983). Le rire, suite. París: Denoël Gonthier.

Fromilhague, C. (1995). Les figures de style. París: Nathan.

Genette, G. (1982). Palimpsestes. La littérature au sécond degré. París: Éditions du Seuil.

Groensteen, T. ( 2011). Système de la bande dessinée. París: Presse Universitaire de France.

Gross, A. G. (2009). Toward a Theory of Verbal-Visual Interaction: The Example of Lavoisier. Rhetoric Society Quarterly, 39(2), 147-169.

Groupe $\mu$. (1992). Traité du Signe Visuel. Pour une rhétorique de l'image. París: Seuil.

Gubern, R. (1972). El lenguaje de los comics. Barcelona: Península.

Haberman, S.J. (1973). The analysis of residuals in cross-classified tables. Biometrics, 29, 205-220.

Hoek, L. (2002). Timbres-poste et intermédialité: sémiotique des rapports texte/image. Protée, 30(2), 33-44.

Jewitt, C. (2009). (Ed). The Routledge Hanbook of Multimedial Analysis. Londres: Routledge. 
Joly, M. (2005). L'image et les signes: approche sémiologique de l'image fixe. París: Armand Colin.

Kress, G. (2010). Multimodality: A social semiotic approach to contemporary communication. Londres: Routledge.

Kress, G. y Van Leeuwen, T. (2006). Reading images. The grammar of visual design. Nueva York: Routledge.

Martinec, R. y Salway, A. (2005). A system for image-text relations in new (and old) media. Visual communication, 4(3): 337-371.

McCloud, S. (1994). Understanding comics. The Invisible Art. New York: Harper Perennial.

Molinié, G. (1993). La stylistique. París: Presses Universitaires de France.

Pedrazzini, A. (2012). Dos presidentes bajo la mirada del dibujante satírico: el caso de la caricatura política y sus recursos en dos producciones de Francia y Argentina. Antíteses, 5(9), 25-53.

Pedrazzini, A. (2015). Las incoherencias insólita y paradójica en la caricatura política: juegos verbales y visuales en la ruptura de lo previsible. DeSignis, 22, 99-109.

Pedrazzini, A. y Scheuer, N. (2010). La interacción lingüística e ícono-plástica en la producción de caricaturas políticas: un estudio funcional y retórico. IRICE Nueva época, 21, 95-111.

Pedrazzini, A. y Scheuer, N. (2012). Figuras retóricas verbales y visuales en la conformación de un estilo de autor: las caricaturas políticas del semanario satírico francés Le Canard enchaîné. Cultura, lenguaje y representación, X, 111-128.

Peeters, B. (2003). Lire la bande dessinée. París: Flamarion.

Reboul, O. (1993). La rhétorique. París: Presses Universitaires de France.

Robrieux, J-J. (1993). Eléments de rhétorique et d'argumentation. París: Dunod.

Rojas Mix, M. (2006). El Imaginario. Civilización y cultura del siglo XXI. Buenos Aires: Prometeo Libros.

Samson, A. y Huber, O. (2007). The interaction of cartoonist's gender and formal features of cartoons. Humor. International Journal of Humor Research, 20, 1-25.

Tillier, B. (2005). A la charge! la caricature en France de 1789 à 2000. París: Les Editions de l’Amateur.

Tsakona, V. (2009). Language and image interaction in cartoons: Towards a multimodal theory of humor. Journal of Pragmatics, 41, 1171-1188.

Unsworth, L. y Cléirigh, C. (2009). Multimodality and reading. The construction of meaning through image-text interaction. En C. Jewitt (Ed.), The Routledge Handbook of Multimodality. Londres: Routledge, 151-169. 
Vilches, L. (1984). La lectura de la imagen. Prensa, cine, televisión. Buenos Aires: Paidós.

Abstract: In this paper we study the ways in which verbal and visual modes are articulated in multimodal cartoons, focusing on: 1) the functions each mode accomplishes to build the referenced situation (theme) and the fictional situation (humorous play) and 2) the verbal, visual and mixed resources used. The corpus of cartoons analysed was obtained in the frame of a questionnaire in which cartoonists were asked to choose the cartoon that best represented their work. A gradation of modal participation in the construction of both the referenced and fictional situations was identified. Grade 1 consists in the distribution of modal labour; Grade 2 in partial conjunction, while in Grade 3 conjunction is total.

Key words: verbal-visual relation - multimodality - intermodality - cartoon - resources - rhetorical figures.

Resumo: Este artigo aborda as diversas formas e graus em que os modos verbal e visual estão relacionados ao humor gráfico multimodal, enfocando as funções que assumem para construir a situação referida (tema) e a situação fictícia (jogo humorístico), bem como em os recursos verbais, visuais e mistos utilizados. O corpus de vinhetas humorísticas analisadas foi obtido a partir de um questionário, no qual os humoristas gráficos foram convidados a escolher uma vinheta representativa do seu estilo. Propomos uma gradação de participação modal na construção das situações referidas e fictícias: distribuição de trabalho modal (grau 1), conjunção parcial (grau 2) e total (grau 3).

Palavras chave: multimodalidade - intermodalidade - humor gráfico.

[Las traducciones de los abstracts al inglés y portugués fueron supervisadas por el autor de cada artículo]

Sobre la relación verbalvisual en el humor gráfico y sus recursos fue publicado de la página 123 a página141 en Cuadernos del Centro de Estudios de Diseño y Comunicación Nº74 